\title{
Vascular Toxicity of Phosphate in Chronic Kidney Disease
} - Beyond Vascular Calcification -

\author{
Priscilla Gross, BSc; Isabelle Six, PhD; Said Kamel, PhD; Ziad A. Massy, MD, PhD
}

\begin{abstract}
Chronic kidney disease (CKD) is characterized by high cardiovascular morbidity/mortality, which is linked in part to vascular calcification (VC) and endothelial dysfunction (ED). Hyperphosphatemia, a feature of CKD, is a well-known inducer of VC in preclinical models and is associated with poor outcomes in epidemiological studies. However, it remains to be seen whether lowering phosphate levels in CKD patients reduces VC and the morbidity/mortality rate. Furthermore, it is now clear from preclinical and clinical studies that phosphate is involved in ED. The present article reviews the direct and indirect mechanisms (eg, via fibroblast growth factor 23 and/or parathyroid hormone) by which hyperphosphatemia influence the onset of VC and ED in CKD. (Circ $J$ 2014; 78: 2339-2346)
\end{abstract}

Key Words: Endothelial dysfunction; Phosphate; Phosphate-regulating hormones; Vascular calcification

$\mathbf{P}$ hosphate, principally provided by food, is involved in many physiological processes: it buffers the intracellular $\mathrm{pH}$, ensures the stability of the skeleton and contributes to many essential biological functions (eg, DNA synthesis, cell membrane phospholipids, energy metabolism and intracellular signaling pathways that are regulated by phosphorylation/dephosphorylation).

The physiological concentration of phosphate $(0.8$ $1.5 \mathrm{mmol} / \mathrm{L}$ ) is tightly regulated by, among others, the fibroblast growth factor 23 (FGF23)/Klotho axis, parathyroid hormone (PTH) and calcitriol (the active form of vitamin D). ${ }^{1}$

In chronic kidney disease (CKD), the progressive loss of functional nephrons induces retention of phosphate, which in turn leads to (1) an increase in calcium/phosphate products and (2) FGF23 synthesis. With the aim of preventing hyperphosphatemia, FGF23 decreases circulating levels of calcitri$\mathrm{ol}$, thus inhibiting intestinal phosphate and calcium absorption. $\mathrm{PTH}$, the overexpression of which is triggered by hypocalcemia, stimulates bone resorption for the primary purpose of restoring calcemia but in doing so it increases phosphatemia and thus the calcium/phosphate products. During the course of CKD, Klotho's downregulation in both the parathyroid gland and the kidney results in the loss of FGF23 being able to respectively (1) decrease PTH expression and (2) inhibit renal phosphate reabsorption. In late-stage $\mathrm{CKD}$, the few remaining functional nephrons are no longer able to eliminate phosphate and a vicious circle (referred to as secondary hyperparathyroidism) appears with hyperphosphatemia as the ultimate consequence. $^{2}$

Patients with CKD are considered to be in the "highest risk group" for cardiovascular (CV) morbidity/mortality. 3,4
In epidemiological studies of CKD patients and the general population, high phosphate levels are associated with CV disease (CVD). The association is even observed in early-stage CKD and is independent of other traditional CV risk factors. ${ }^{5,6}$

Along with other factors, hyperphosphatemia is involved in the development of vascular calcification (VC) and endothelial dysfunction (ED), ${ }^{7-9}$ both of which are major nontraditional CV risk factors for CKD. Phosphate is able to act either directly on these parameters or indirectly via the FGF23/Klotho and PTH axes (Figure 1).

We review the various effects of hyperphosphatemia on $\mathrm{CV}$ parameters, with a focus on its emerging role in ED. The efficacy of current therapies for improving phosphate-related $\mathrm{CV}$ outcomes is also discussed.

\section{Direct Effects of Phosphate on CV Calcification and ED}

\section{Epidemiological and Interventional Studies}

VC is deposition of calcium/phosphate, mostly as apatite, in the blood vessels, myocardium and cardiac valves. Calcification of both the intima and media occurs in CKD, ${ }^{10}$ resulting in the stiffness of the large arteries (as evidenced by a higher pulse wave velocity) and thus promotion of CV morbidity/ mortality.

The results of several epidemiological studies have highlighted an association between serum phosphate levels and VC in stage 5D CKD patients, ${ }^{11,12}$ in early-stage CKD patients and in the general population (in whom serum phosphate levels are still within the normal range). ${ }^{13,14}$

Indeed, 2 elegant prospective studies of large cohorts of

Received July 6, 2014; accepted July 7, 2014; released online July 31, 2014

INSERM Unit 1088, Jules Verne University of Picardie, Amiens (P.G., I.S., S.K., Z.A.M.); Amiens University Medical Center, Amiens

(S.K.); and Division of Nephrology, Ambroise Paré Hospital and Paris-Ile-de-France-Ouest University, Boulogne Billancourt (Z.A.M.), France

Mailing address: Professor Ziad A. Massy, MD, PhD, FERA, Chief, Division of Nephrology, Ambroise Paré Hospital, Paris-Ile-de-France-

Ouest University (UVSQ), 9 avenue Charles de Gaulle, F-92100 Boulogne Billancourt cedex, France. E-mail: ziad.massy@apr.aphp.fr

ISSN-1346-9843 doi:10.1253/circj.CJ-14-0735

All rights are reserved to the Japanese Circulation Society. For permissions, please e-mail: cj@j-circ.or.jp 


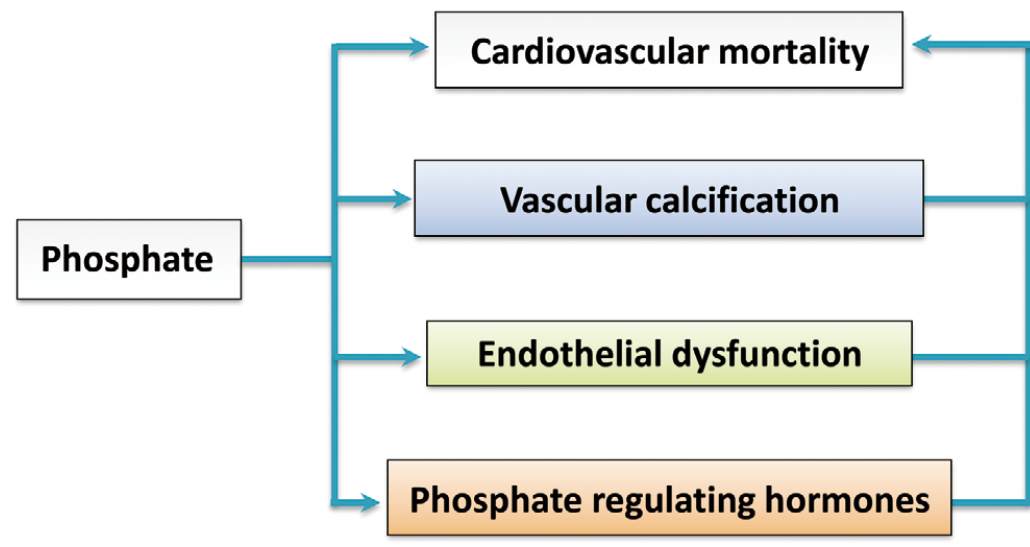

Figure 1. Cardiovascular (CV) mortality related to phosphate in chronic kidney disease (CKD). Phosphate is a major risk factor and has direct actions on both vascular calcification (VC) and endothelial dysfunction (ED). Furthermore, phosphateregulating hormones are responsible for the indirect effects of phosphate. Despite the association between phosphate-regulating hormones on the one hand and VC, ED and CV mortality on the other, it is not yet clear whether increased levels of these hormones in CKD are beneficial or detrimental.

healthy adults have demonstrated that phosphorus levels at the upper limit of the normal range are independently associated with a greater likelihood and a more rapid progression of coronary artery calcium. ${ }^{14,15}$ In a study involving 439 multi-ethnic participants with moderate CKD but no clinical signs of CVD, Adeney et al reported that each $1 \mathrm{mg} / \mathrm{dl}(0.32 \mathrm{mmol} / \mathrm{L})$ increment in phosphate level is strongly $(\mathrm{P}=0.002)$ and independently associated with a higher prevalence of calcification. ${ }^{13}$

Actual therapy to manage hyperphosphatemia in endstage CKD includes, among others, oral phosphate binders such as calcium acetate, sevelamer or lanthanum. The published results of randomized controlled trials (RCTs) have not clearly established whether normalizing serum phosphate levels reduces VC and/or affects survival. ${ }^{16,17}$ The first RCT (conducted by Chertow et al on 200 hemodialysis patients) found that after 52 weeks of follow-up, patients receiving calcium acetate displayed higher calcium scores for the coronary arteries and thoracic aorta than those treated with sevelamer. ${ }^{18}$ In contrast, the BRIC study involving 101 hemodialysis patients failed to observe a beneficial effect of lowering serum phosphate levels on progression of coronary artery calcium after a 12-week follow-up period. ${ }^{19}$ Similar results were reported by Qunibi et al on a larger cohort of hemodialysis patients monitored over a 12-month period. ${ }^{20}$

More recently, a pilot RCT looked at the VC risks and benefits associated with the use of phosphate binders in earlystage CKD. ${ }^{21}$ Although phosphate binders effectively lowered serum and urinary phosphate levels in patients not yet on dialysis, methodological problems prevented the researchers from drawing firm conclusions regarding $\mathrm{VC} .^{21}$

Compared with healthy people, CKD patients have impairments in endothelium-dependent relaxation, emphasizing the endothelium's essential role in CKD. ${ }^{22}$ Recent data have evidenced a relationship between ED and VC, with the first appearing earlier during the course of $\mathrm{CKD} .{ }^{23}$ Both these factors contribute to arterial stiffness, left ventricular hypertrophy and ultimately heart failure, the major cause of death in CKD patients. It remains to be determined whether managing the ED can delay VC and affect CV mortality.

Shuto et $\mathrm{al}^{24}$ provided the first in vivo evidence of a direct contribution of phosphate to the onset of ED. They measured the flow-mediated dilation (FMD) of the brachial artery (as an indicator of endothelial function) in 11 healthy subjects who had been provided meals containing either $400 \mathrm{mg}$ or $1,200 \mathrm{mg}$ of phosphate. The higher dietary phosphorus load was associ- ated with a significantly greater serum phosphate level after $2 \mathrm{~h}$ and a significantly lower FMD.

In line with Shuto et al's results, several clinical trials have reported beneficial effects of lowering phosphate levels on ED. Caglar et al studied 50 nondiabetic, hyperphosphatemic patients at CKD stage 4 and observed that an 8 -week course of treatment with sevelamer was associated with less inflammation, higher fetuin-A levels and better endothelial function, compared with calcium acetate. ${ }^{25}$ Yilmaz et al for their part recently reported, in a similar cohort, a modulation of FGF23 levels by phosphate binders, independently associated with improvement of endothelial function. ${ }^{26}$

\section{In Vitro Studies}

Phosphate-induced VC has been extensively studied in recent years, whereas the exploration of phosphate's involvement in ED is only just emerging. The 2 phenomena share some common underlying mechanisms. After entry via the ubiquitous sodium-phosphate cotransporters PiT-1 and PiT-2,27 phosphate induces the apoptosis of both vascular smooth muscle cells (VSMCs) and endothelial cells (ECs) resulting in (1) the release of matrix vesicles (MVs) able to calcify blood vessels and (2) endothelial damage. Moreover, by increasing reactive oxygen species (ROS) production, phosphate decreases the bio-availability of nitric oxide (NO), impairs endotheliumdependent relaxation and triggers the osteochondrogenic switch in VSMCs. A number of specific VC- or ED-promoting actions of phosphate have also been reported and are discussed later (Figure 2).

Osteochondrogenic Switch of VSMCs VSMCs cultured with high phosphate levels lose the expression of smooth-muscle specific genes (eg, $\alpha$-actin, smooth muscle myosin heavy chain and SM22 $\alpha)^{28}$ and acquire an osteochondrogenic phenotype. The latter is characterized by osteogenic markers (such as alkaline phosphatase) and upregulation of the Cbfa1/Runx2 transcription factor leading to the synthesis of osteocalcin and osteopontin. ${ }^{29,30}$

Emerging Role of microRNA (miRNA) in VC Recent research has evidenced the involvement of miRNA in phosphateinduced phenotypic switching. Our lab demonstrated that phosphate induces $\mathrm{VC}$ through a mechanism involving the downregulation of miR-145/143, known to be involved in the determination of the contractile phenotype of VSMCs, and the upregulation of miR-223. ${ }^{31}$ Various studies have evidenced the downregulation of miR-125b, miR-221, miR-222, miR- 


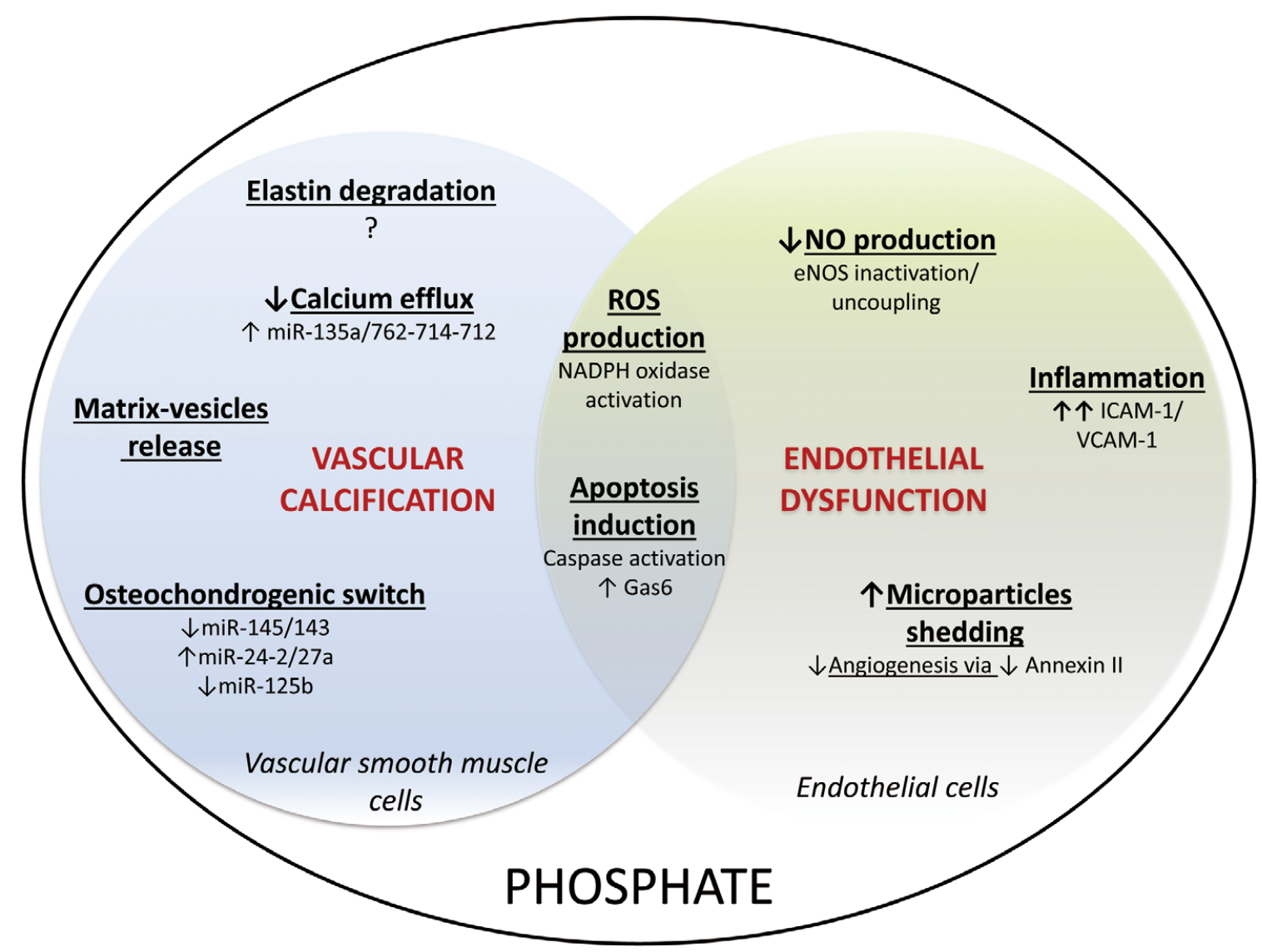

Figure 2. Schematic representation of the mechanisms of phosphate-induced vascular calcification (VC) and endothelial dysfunction (ED). eNOs, endothelial nitric oxide synthase; ICAM, intercellular adhesion molecule; ROS, reactive oxygen species; VCAM, vascular cell adhesion molecule.

24-2, miR-27a and miR-31 during in vitro VC under high phosphate conditions. Downregulation of miR-24-2 and 27a, known to be involved in bone formation via inhibition of Runx2 , might lead to a VSMC switch. ${ }^{32}$ It has been suggested that miR-221 and -222 act synergistically to initiate VC but are then downregulated. ${ }^{33}$ miR-31 has been shown to be involved in the osteogenic differentiation of mesenchymal cells. ${ }^{34}$ Lastly, miR-125b downregulation induces upregulation of the transcription factor Ets, a potent repressor of VSMC marker genes. ${ }^{35}$

Some authors have sted that phosphate-induced VC may involve the elevation of intracellular $\mathrm{Ca}^{2+}$ concentrations as a result of the induction of miR-135a, miR-762, miR-714, and miR-712, implicated in the repression of transporters involved in $\mathrm{Ca}^{2+}$ efflux. ${ }^{36}$

Elastin Degradation Phosphate triggers and accelerates the mineralization induced by elastin-derived peptides. ${ }^{37,38}$ Whether phosphate also degrades elastin, thus favoring $\mathrm{VC}$, remains to be confirmed.

Inhibition of Monocyte/Macrophage Osteoclast Differentiation We recently demonstrated that phosphate can inhibit osteoclast differentiation into monocytes/macrophages in vitro; this finding strongly suggests that $\mathrm{VC}$ is the result of a vascular remodeling process similar to that observed in bone remodeling. ${ }^{39}$ It remains to be seen whether this mechanism occurs in vivo.

Release of MVs The calcification process induced by phosphate is initiated by the release of calcium/phosphate-rich MVs from living VSMCs. These vesicles contain annexin-II and -VI (membrane-associated proteins known to mediate $\mathrm{Ca}^{2+}$ influx) and are able to calcify extensively. ${ }^{40}$

Induction of Apoptosis Phosphate induces the apoptosis of VSMCs in a time-dependent manner. In turn, apoptosis triggers the release of apoptotic bodies containing preformed calcium/phosphate products and with strong calcification ability. ${ }^{41}$

Endothelial integrity is essential for normal endothelial function. Using an ex vivo murine thoracic aorta model, we recently demonstrated that 8 days of exposure to high phosphate levels results in EC loss. ${ }^{42}$ Di Marco et al reported that high phosphate levels increase ROS production in ECs, causing disruption of the mitochondrial membrane potential and then apoptosis via caspase activation. ${ }^{43}$

Phosphate's pro-apoptotic effect on ECs has been demonstrated in other studies. ${ }^{44}$

Increased ROS Production The exposure of ECs and VSMCs to high phosphate levels induces the intracellular production of ROS, mainly $\mathrm{H}_{2} \mathrm{O}_{2}$, via NADPH oxidase activation. ${ }^{25,42,44,45} \mathrm{H}_{2} \mathrm{O}_{2}$ has been shown to induce the osteochondrogenic switch of VSMCs through Runx2 activation. ${ }^{46}$ ROS are 
considered as endothelium-derived contracting factors able to induce contraction in dysfunctional endothelium. We recently demonstrated that high phosphate levels have a direct, ROSmediated vasoconstrictor effect. ${ }^{42}$

Decreased NO Production All the existing studies are consistent on a decrease in NO production after acute exposure to high phosphate levels. ${ }^{24,45}$ A study using bovine aortic ECs showed that high levels of phosphate decrease the intracellular $\mathrm{Ca}^{2+}$ concentration that could inactivate endothelial NO synthase (eNOS) ${ }^{44}$ Moreover, high phosphate levels also lead to eNOS phosphorylation (on Thr495) and inactivation through phosphokinase $\mathrm{C}$ activation. ${ }^{24,42} \mathrm{We}$ recently demonstrated for the first time that phosphate induces eNOS uncoupling (via the oxidation of tetrabiopterin) in a murine brain EC line. ${ }^{47}$

Induction of Microparticle Shedding and Inhibition of Angiogenesis Endothelial microparticles (EMPs) are vesicles of $0.1-1 \mu \mathrm{m}$ in size, produced by plasma membrane shedding after cell activation or apoptosis and characterized by the externalization of phosphatidylserine and the presence of ECspecific surface antigens. Some recent findings suggest that EMPs are not only markers of endothelial damage but may also be involved in ED, probably because of their protein content. ${ }^{48}$

In an elegant study, Di Marco et $\mathrm{al}^{49}$ recently demonstrated that high phosphate levels induces EMP shedding. After observing the large number of annexin-II positive EMPs, the researchers speculated that the induced EMP shedding decreases intracellular levels of annexin-II and thus results in impaired ECs with thrombotic, inflammatory and anti-angiogenic properties.

\section{Animal Studies}

The in vitro effects of high phosphate levels on VC and ED have been confirmed in vivo in animal models of CKD fed a high-phosphate diet. ${ }^{50-52}$

In an indirect confirmation of the role of hyperphosphatemia, our team found that the administration of sevelamer or lanthanum to uremic, apolipoprotein-E-deficient mice prevented uremia-induced hyperphosphatemia and slowed both VC and atherosclerosis. ${ }^{53,54} \mathrm{We}$ also reported that calcium carbonate had beneficial effects on VC (despite an increase in calcemia), supporting the predominant role of phosphate in the promotion of VC in CKD. ${ }^{55}$

We recently characterized the in vivo role of phosphate in the onset and progression of ED, independently of VC. ${ }^{42} \mathrm{We}$ demonstrated that in sham-operated mice, a high-phosphate diet decreased acetylcholine-induced relaxation and increased phenylephrine-induced contraction. These effects of phosphate have been linked to both the loss of ECs and the induction of the expression of adhesion molecules, suggesting that phosphate could induce inflammation in vivo. In that study, sevelamer was able to prevent the EC loss in vitro and attenuate ED and the phosphate-associated induction of adhesion molecules in CKD mice. We subsequently used the same animal model to test the effect of sevelamer administration on CKD-related CV abnormalities. ${ }^{56}$ In line with the observed decrease in both hyperphosphatemia and FGF23 levels, sevelamer treatment reduced ED, aortic stiffness and left ventricular diastolic dysfunction and thus prevented the progression of left ventricular hypertrophy. We reported that sevelamer treatment is also associated with a decreased expression of proteins related to myocardial hypertrophy compared with CKD placebo mice. Interestingly, there was no clear correlation between FGF23 levels and cardiac abnormalities, suggesting that the benefits of sevelamer administration were mainly related to its effects on phosphatemia rather than on FGF23.

\section{Indirect Effects of Phosphate on CV Calcification and ED}

As mentioned before, phosphate levels are maintained within the normal range in early-stage CKD by a compensatory increase in FGF23 and PTH levels. Notwithstanding the proven association of these phosphate-regulating hormones with $\mathrm{CV}$ outcomes, most of the epidemiological studies linking phosphatemia with CV morbidity/mortality have not measured serum levels. Moreover, daily urinary phosphate excretion (a better marker of phosphate load than the serum phosphate level) has rarely been evaluated in these epidemiological studies.

Lastly, the phosphate binders that reportedly reduce VC and ED in animal and clinical studies are also known to modulate FGF23 levels; this makes it more difficult to evaluate the role of phosphate on CVD in vivo.

\section{PTH}

PTH was first described as a calcium-regulating hormone with direct actions on bone and kidney and indirect effects on the gastrointestinal tract. The elevated levels of PTH seen in CKD are related to phosphate retention and the resulting hypocalcemia. Characterization of the CV effects of PTH has been accelerated by the recent discovery of the PTH receptor in VSMCs and ECs (as well as in cardiomyocytes). ${ }^{57}$

Epidemiological and Interventional Studies PTH levels are associated with $\mathrm{CV}$ mortality even in the general population with a "normal" PTH range. Indeed, in the Uppsala Longitudinal Study of Adult Men, a community-based cohort of elderly men followed up for a median of 9.7 years, plasma PTH levels at the upper limit of the normal range were strongly and independently associated with a greater risk of CV mortality. 58

In contrast, increased CV mortality is also found in patients with confirmed primary hyperparathyroidism (PHPT) and secondary hyperparathyroidism, even after parathyroidectomy. Furthermore, some clinical studies have demonstrated that controlling PTH levels (with cinacalcet) in hemodialysis patients does not reduce their CV risk. ${ }^{59-61}$

Cinacalcet is an allosteric co-activator of the calcium-sensing receptor (CaSR) and acts by lowering the blood $\mathrm{Ca}^{2+}$ concentration needed to inhibit PTH release.

An improvement of ED after parathyroidectomy has been reported by Lumachi et al in 22 patients with confirmed PHPT. ${ }^{62}$ Choi et al ${ }^{63}$ recently tested the effect of cinacalcet on endothelial function. Their study results demonstrated that cinacalcet alone (ie, in the absence of vitamin D supplementation) improves ED by decreasing oxidative stress and increasing serum NO production. All these various parameters returned to their pretreatment concentrations after withdrawal of cinacalcet.

In Vitro Studies The precise role of PTH on VC is unclear. It has been reported that high PTH concentrations induce in vitro collagen production by VSMCs; in contrast, PTH inhibits calcification in a dose-dependent manner. ${ }^{64}$

Animal Studies Conflicting results are also found regarding the effect of PTH on VC in animal models. Although Shao et al demonstrated a beneficial effect of PTH administration on $\mathrm{CV}$ calcification in diabetic mice ${ }^{65}$ Neves et al reported that PTH replacement therapy in parathyroidectomized CKD rats results in aortic calcification. ${ }^{66}$ These discrepancies may be related to the type of PTH used and the difference in injec- 


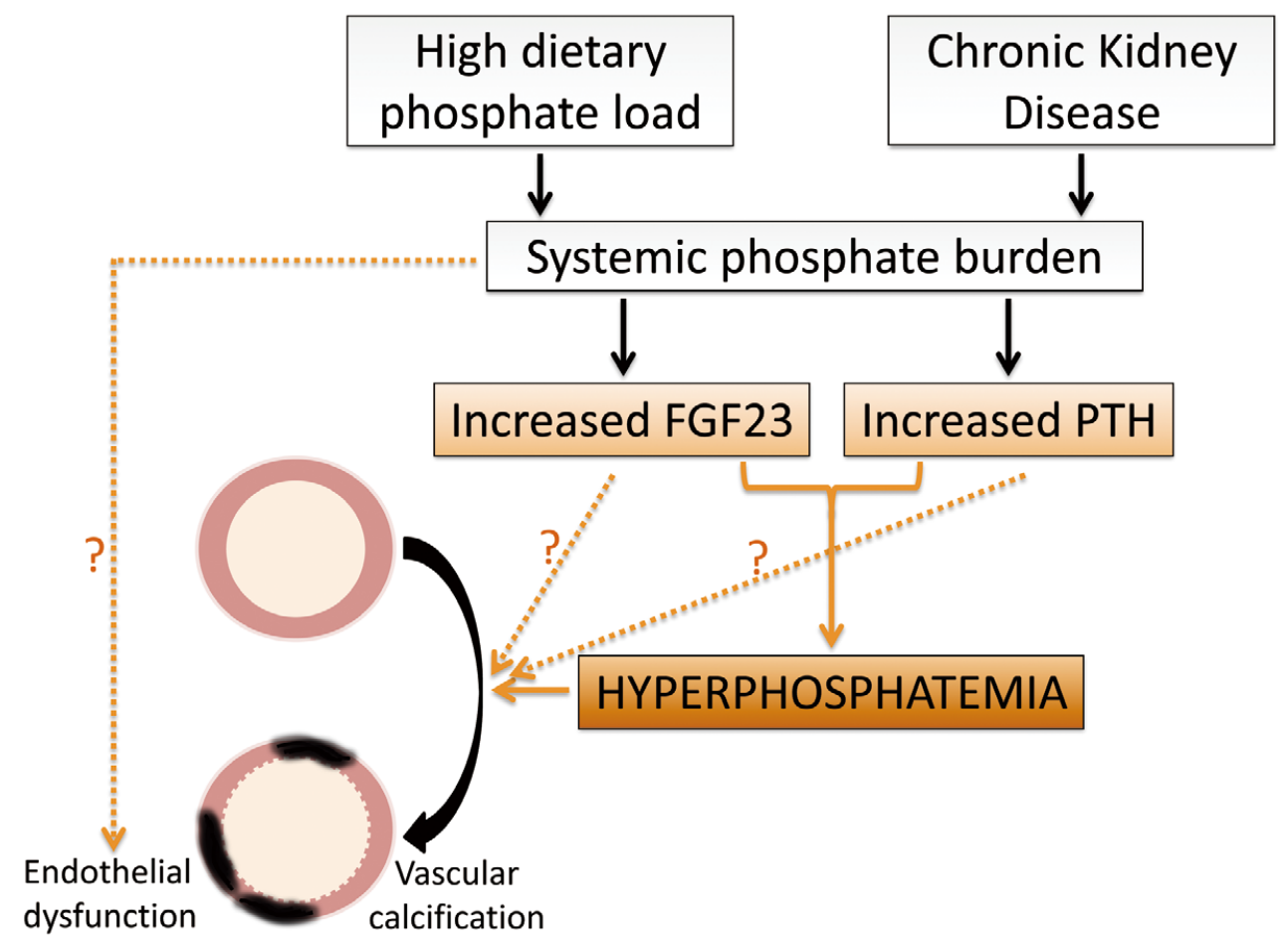

Figure 3. Potential role of phosphate in vascular damage: beyond chronic kidney disease (CKD). A systemic phosphate burden can result from a high dietary phosphate load or a low number of functional nephrons (as in CKD). In CKD, elevated production of FGF23 and parathyroid hormone (PTH) (which normally reduces the phosphate burden) leads to hyperphosphatemia and vascular alterations. The endothelial dysfunction caused by a long-term excessive phosphate burden (from a Western diet) may constitute the link between high-normal phosphate levels and cardiovascular mortality in the general population.

tion mode (ie, intermittent vs. continuous). It is noteworthy that animal studies (notably from our lab) have observed beneficial, PTH-independent effects of cinacalcet in term of VC via activation of the CaSR present in the vasculature. ${ }^{67,68}$

\section{FGF-23/KIotho Axis}

Isakova et al demonstrated that FGF23 is the first factor to be elevated in the early stage of CKD, to prevent hyperphosphatemia. ${ }^{69}$ Membrane-bound Klotho acts as an obligatory coreceptor for FGF23 in the kidney, whereas soluble Klotho functions as an endocrine substance. The reported early and graded decrease in Klotho expression during CKD results in the loss of the ability of FGF23 to decrease both PTH expression and hyperphosphatemia, despite the elevated serum levels of this factor.

Epidemiological and Interventional Studies Elevated levels of FGF23 and decreased levels of Klotho are associated with CV mortality in CKD patients and/or the general population. ${ }^{70,71}$

An association between variations in FGF23 levels and VC has also been reported. Whether the accumulation of FGF23 exerts protective effect or, on the contrary, is detrimental remains a matter of debate, suggesting the complexity of FGF23 action. Indeed, a study of 142 patients at different CKD stages found that plasma FGF23 levels were positively and independently associated with coronary artery calcium (even in earlystage disease). ${ }^{72}$ In contrast, Tamei et al observed a negative association between FGF23 and the progression of aortic arch calcification and suggested that the excessive accumulation of FGF23 may inhibit the calcification process in hemodialysis patients. $^{73}$

Regarding endothelial function, the PIVUS study involving elderly subjects with normal renal function reported an association between circulating levels of FGF23 (within the normal range) on the one hand and impaired endothelium-dependent relaxation, endothelium-independent relaxation and arterial stiffness on the other. ${ }^{74}$ Kitagawa et al demonstrated that low serum levels of soluble Klotho are independently associated with vascular stiffness in CKD patients. ${ }^{75}$

In Vitro Studies To date, a direct effect of FGF23 on VC has not been reported. It is widely admitted that Klotho deficiency is harmful. Klotho is able to act directly on calcification by both suppressing the sodium-dependent uptake of phosphate and moderating the osteochondrogenic switch of VSMCs. ${ }^{76,77}$ Thus, the abnormally low Klotho expression observed in CKD might contribute to arterial calcification in vivo. This hypothesis has been challenged recently by Jimbo et al who demonstrated that FGF23 amplifies the phosphateinduced VC in condition of Klotho overexpression. ${ }^{78}$ It has also been reported that Klotho has beneficial effects on vascular function. Klotho protects ECs from oxidative stressinduced apoptosis by upregulating the expression of the antioxidant enzyme, manganese superoxide dismutase. ${ }^{79-81}$ Moreover, Klotho maintains endothelial integrity by regulating $\mathrm{Ca}^{2+}$ influx in ECs. ${ }^{82}$

Concerning the action of FGF23 on ED, we recently dem- 
onstrated $^{83}$ that ex vivo treatment of murine thoracic aortas with FGF23 leads to an increase in ROS production and further contraction. We also highlighted that treatment with Klotho directly induces vessel contraction through ROS production. Combining phosphate or FGF23 with Klotho induced vessel relaxation - through Klotho induced NO production. Lastly, the combination of Klotho, FGF23 and phosphate resulted in impaired endothelium-dependent relaxation, suggesting that direct Klotho supplementation would not be effective in CKD.

Animal Studies Mice lacking FGF23 or Klotho gene have widespread VC and early death because of phosphate accumulation. ${ }^{84,85}$ Nevertheless, supporting the complexity of FGF23 action, its expression has been found in calcified segments of human carotid arteries. ${ }^{86}$ Moreover, CKD mice fed a highphosphate diet exhibit high levels of FGF23, without overt hyperphosphatemia, correlating with arterial calcification. Faul et al recently demonstrated that high serum levels of FGF23 induced left ventricular hypertrophy in mice and highlighted the direct, pathogenic, "off-target" effect of FGF23 because of the unspecific occupation of its receptor, thereby suggesting a beneficial effect of managing FGF23 levels. ${ }^{87}$ However, Shalhoub et al showed that lowering FGF23 levels in CKD rats resulted in increased aortic calcification and mortality. ${ }^{88} \mathrm{Lim}$ et $a l,{ }^{77}$ for their part, elegantly demonstrated that Klotho and FGF receptor (FGFR)-1/3 deficiencies (as found in CKD) favor the development of arterial calcification and mediate resistance to the vascular beneficial effect of FGF23. In their study, the use of vitamin D receptor activators restored Klotho expression and revealed the anticalcific effects of FGF23. Other authors also report, using murine models of CKD, that Klotho overexpression or upregulation by vitamin $\mathrm{D}$ receptor activators reduces $\mathrm{VC} .{ }^{76,89}$

Taken together, the results of these studies suggest that in combination with oral phosphate binders, treatment strategies regarding VC should focus on restoring "normal" Klotho expression (and thus preventing "off-target" effects of FGF23) rather than decreasing FGF23 levels in CKD. In terms of endothelial function, it has been reported that Klotho deficiency impairs both endothelial function (which was improved by Klotho gene delivery) and permeability (associated with increased apoptosis and downregulation of cadherin expression).$^{90}$ Memo is a newly discovered downstream effector of FGFR signaling. ${ }^{91}$ Memo-deficient mice have some characteristics in common with FGF23/Klotho mice (namely, a short life span, low PTH levels and elevated calcitriol and calcium levels) but differ in terms of phosphate levels. In vitro experiments revealed that Memo downregulation only partially inhibits FGFR signaling; this could explain why a lack of Memo in vivo does not result in hyperphosphatemia. Those observations have confirmed the predominant role of FGF23/Klotho in phosphate homeostasis. Further research is required to determine whether (1) the tissue expression of Memo varies in CKD and (2) modulating its expression can slow or even prevent calcification.

\section{Conclusions}

Phosphate levels are associated with CV risk in both CKD patients and the general population. We have summarized recent data concerning the direct and indirect effects of hyperphosphatemia on VC and ED. Nevertheless, the mechanisms underlying the association between high-normal phosphate levels and $\mathrm{CV}$ risk in the general population have yet to be characterized. Many in vitro and in vivo studies have high- lighted an acute effect of hyperphosphatemia on ED. The high phosphate content of the Western diet may cause long-term, excessive phosphate loading (without overt hyperphosphatemia) ${ }^{92}$ that leads to ED and then CVD. It is noteworthy that post-prandial blood glucose elevation is a well-established risk factor for CVD. Hence, ED caused by post-prandial hyperphosphatemia could be the link between high-normal phosphate levels and the $\mathrm{CV}$ risk in the general population (Figure 3 ).

\section{References}

1. Berndt TJ, Schiavi S, Kumar R. 'Phosphatonins' and the regulation of phosphorus homeostasis. Am J Physiol Renal Physiol 2005; 289: F1170-F1182.

2. Quarles LD. Role of FGF23 in vitamin D and phosphate metabolism: Implications in chronic kidney disease. Exp Cell Res 2012; 318: 1040-1048.

3. Foley RN, Parfrey PS, Sarnak MJ. Clinical epidemiology of cardiovascular disease in chronic renal disease. Am J Kidney Dis 1998; 32: S112-S119.

4. Culleton BF, Larson MG, Wilson PW, Evans JC, Parfrey PS, Levy $\mathrm{D}$, et al. Cardiovascular disease and mortality in a community-based cohort with mild renal insufficiency. Kidney Int 1999; 56: 22142219.

5. Palmer SC, Hayen A, Macaskill P, Pellegrini F, Craig JC, Elder GJ, et al. Serum levels of phosphorus, parathyroid hormone, and calcium and risks of death and cardiovascular disease in individuals with chronic kidney disease: A systematic review and meta-analysis. JAMA 2011; 305: 1119-1127.

6. McGovern AP, de Lusignan S, van Vlymen J, Liyanage H, Tomson $\mathrm{CR}$, Gallagher $\mathrm{H}$, et al. Serum phosphate as a risk factor for cardiovascular events in people with and without chronic kidney disease: A large community based cohort study. PloS One 2013; 8: e74996, doi:10.1371/journal.pone.0074996.

7. Weiner DE, Tighiouart DE, Elsayed EF, Griffith JL, Salem DN, Levey AS. The Framingham predictive instrument in chronic kidney disease. J Am Coll Cardiol 2007; 50: 217-224.

8. London GM, Guérin AP, Marchais SJ, Métivier F, Pannier B, Adda $\mathrm{H}$. Arterial media calcification in end-stage renal disease: Impact on all-cause and cardiovascular mortality. Nephrol Dial Transplant 2003; 18: $1731-1740$.

9. Diaz-Buxo JA, Woods HF. Protecting the endothelium: A new focus for management of chronic kidney disease. Hemodial Int 2006; 10: $42-48$.

10. Proudfoot D, Shanahan CM. Biology of calcification in vascular cells: Intima versus media. Herz 2001; 26: 245-251.

11. Mazhar AR, Johnson RJ, Gillen D, Stivelman JC, Ryan MJ, Davis CL, et al. Risk factors and mortality associated with calciphylaxis in end-stage renal disease. Kidney Int 2001; 60: 324-332.

12. Raggi P, Boulay A, Chasan-Taber S, Amin N, Dillon M, Burke SK, et al. Cardiac calcification in adult hemodialysis patients: A link between end-stage renal disease and cardiovascular disease? J Am Coll Cardiol 2002; 39: 695-701.

13. Adeney KL, Siscovick DS, Ix JH, Seliger Sl, Shlipak MG, Jenny NS, et al. Association of serum phosphate with vascular and valvular calcification in moderate CKD. J Am Soc Nephrol 2009; 20: $381-387$.

14. Foley RN, Collins AJ, Herzog CA, Ishani A, Kalra PA. Serum phosphorus levels associate with coronary atherosclerosis in young adults. J Am Soc Nephrol 2009; 20: 397-404.

15. Tuttle KR, Short RA. Longitudinal relationships among coronary artery calcification, serum phosphorus, and kidney function. Clin J Am Soc Nephrol 2009; 4: 1968-1973.

16. Isakova T, Gutiérrez OM, Chang Y, Shah A, Tamez H, Smith K. Phosphorus binders and survival on hemodialysis. J Am Soc Nephrol 2009; 20: $388-396$.

17. Winkelmayer WC, Liu J, Kestenbaum B. Comparative effectiveness of calcium-containing phosphate binders in incident U.S. dialysis patients. Clin J Am Soc Nephrol 2011; 6: 175-183.

18. Chertow GM, Burke SK, Raggi P. Sevelamer attenuates the progression of coronary and aortic calcification in hemodialysis patients. Kidney Int 2002; 62: 245-252.

19. Barreto DV, Barreto Fde C, de Carvalho AB, Cuppari L, Draibe SA, Dalboni MA, et al. Phosphate binder impact on bone remodeling and coronary calcification: Results from the BRiC study. Nephron Clin Pract 2008; 110: c273-c283.

20. Qunibi W, Moustafa M, Muenz LR, He DY, Kessler PD, Diaz-Buxo JA, et al. A 1-year randomized trial of calcium acetate versus sevelam- 
er on progression of coronary artery calcification in hemodialysis patients with comparable lipid control: The Calcium Acetate Renagel Evaluation-2 (CARE-2) study. Am J Kidney Dis 2008; 51: 952-965.

21. Block GA, Wheeler DC, Persky MS, Kestenbaum B, Ketteler M, Spiegel DM, et al. Effects of phosphate binders in moderate CKD. $J$ Am Soc Nephrol 2012; 23: 1407-1415.

22. Annuk M, Zilmer M, Lind L, Linde T, Fellström B. Oxidative stress and endothelial function in chronic renal failure. J Am Soc Nephrol 2001; 12: 2747-2752.

23. Budoff MJ, Flores F, Tsai J, Frandsen T, Yamamoto H, Takasu J. Measures of brachial artery distensibility in relation to coronary calcification. Am J Hypertens 2003; 16: 350-355.

24. Shuto E, Taketani Y, Tanaka R, Harada N, Isshiki M, Sato M, et al. Dietary phosphorus acutely impairs endothelial function. $J$ Am Soc Nephrol 2009; 20: 1504-1512.

25. Caglar K, Yilmaz MI, Saglam M, Cakir E, Acikel C, Eyileten T, et al. Short-term treatment with sevelamer increases serum fetuin-A concentration and improves endothelial dysfunction in chronic kidney disease stage 4 patients. Clin J Am Soc Nephrol 2008; 3: 61-68.

26. Yilmaz MI, Sonmez A, Saglam M, Yaman H, Kilic S, Eyileten T, et al. Comparison of calcium acetate and sevelamer on vascular function and fibroblast growth factor 23 in CKD patients: A randomized clinical trial. Am J Kidney Dis 2012; 59: 177-185.

27. Crouthamel MH, Lau WL, Leaf EM, Chavkin NW, Wallingford MC, Peterson DF, et al. Sodium-dependent phosphate cotransporters and phosphate-induced calcification of vascular smooth muscle cells: Redundant roles for PiT-1 and PiT-2. Arterioscler Thromb Vasc Biol 2013; 33: 2625-2632.

28. Montes de Oca A, Madueño JA, Martinez-Moreno JM, Guerrero F, Muñoz-Castañeda J, Rodriguez-Ortiz ME, et al. High-phosphateinduced calcification is related to SM22 $\alpha$ promoter methylation in vascular smooth muscle cells. J Bone Miner Res 2010; 25: 19962005.

29. Chen NX, Duan D, O’Neill KD, Wolisi GO, Koczman JJ, Laclair R, et al. The mechanisms of uremic serum-induced expression of bone matrix proteins in bovine vascular smooth muscle cells. Kidney Int 2006; 70: 1046-1053.

30. Jono S, McKee MD, Murry CE, Shioi A, Nishizawa Y, Mori K, et al. Phosphate regulation of vascular smooth muscle cell calcification. Circ Res 2000; 87: E10-E17, doi:10.1161/01.RES.87.7.e10.

31. Rangrez AY, Massy ZA, Metzinger-Le Meuth V, Metzinger L. miR143 and miR-145: Molecular keys to switch the phenotype of vascular smooth muscle cells. Circ Cardiovasc Genet 2011; 4: 197-205.

32. Hassan MQ, Gordon JA, Beloti MM, Croce CM, van Wijnen AJ, Stein JL, et al. A network connecting Runx2, SATB2, and the miR23a 27a 24-2 cluster regulates the osteoblast differentiation program. Proc Natl Acad Sci USA 2010; 107: 19879-19884.

33. Mackenzie NC, Staines KA, Zhu D, Genever P, Macrae VE. miRNA-221 and miRNA-222 synergistically function to promote vascular calcification. Cell Biochem Funct 2014; 32: 209-216.

34. Gao J, Yang T, Han J, Yan K, Qiu X, Zhou Y, et al. MicroRNA expression during osteogenic differentiation of human multipotent mesenchymal stromal cells from bone marrow. J Cell Biochem 2011; 112: $1844-1856$.

35. Wen P, Cao H, Fang L, Ye H, Zhou Y, Jiang L, et al. miR-125b/Ets1 axis regulates transdifferentiation and calcification of vascular smooth muscle cells in a high-phosphate environment. Exp Cell Res 2014; 322: $302-312$.

36. Gui T, Zhou G, Sun Y, Shimokado A, Itoh S, Oikawa K, et al. MicroRNAs that target $\mathrm{Ca}(2+)$ transporters are involved in vascular smooth muscle cell calcification. Lab Invest J Tech Methods Pathol 2012; 92: 1250-1259.

37. Hosaka N, Mizobuchi M, Ogata H, Kumata C, Kondo F, Koiwa F, et al. Elastin degradation accelerates phosphate-induced mineralization of vascular smooth muscle cells. Calcif Tissue Int 2009; 85: $523-529$.

38. Aikawa E, Aikawa M, Libby P, Figueiredo JL, Rusanescu G, Iwamoto $\mathrm{Y}$, et al. Arterial and aortic valve calcification abolished by elastolytic cathepsin S deficiency in chronic renal disease. Circulation 2009; 119: 1785-1794

39. Mozar A, Haren N, Chasseraud M, Louvet L, Mazière C, Wattel A, et al. High extracellular inorganic phosphate concentration inhibits RANK-RANKL signaling in osteoclast-like cells. J Cell Physiol 2008; 215: 47-54.

40. Chen NX, O'Neill KD, Chen X, Moe SM. Annexin-mediated matrix vesicle calcification in vascular smooth muscle cells. J Bone Miner Res 2008; 23: $1798-1805$.

41. Son BK, Kozaki K, Iijima K, Eto M, Kojima T, Ota H, et al. Statins protect human aortic smooth muscle cells from inorganic phosphate- induced calcification by restoring Gas6-Axl survival pathway. Circ Res 2006; 98: 1024-1031.

42. Six I, Maizel J, Barreto FC, Rangrez AY, Dupont S, Slama M, et al. Effects of phosphate on vascular function under normal conditions and influence of the uraemic state. Cardiovasc Res 2012; 96: 130139.

43. Di Marco GS, Hausberg M, Hillebrand U, Rustemeyer P, Wittkowski W, Lang D, et al. Increased inorganic phosphate induces human endothelial cell apoptosis in vitro. Am J Physiol Ren Physiol 2008; 294: F1381-F1387.

44. Peng A, Wu T, Zeng C, Rakheja D, Zhu J, Ye T, et al. Adverse effects of simulated hyper- and hypo-phosphatemia on endothelial cell function and viability. PloS One 2011; 6: e23268, doi:10.1371/ journal.pone.0023268.

45. Takeda E, Taketani Y, Nashiki K, Nomoto M, Shuto E, Sawada N, et al. A novel function of phosphate-mediated intracellular signal transduction pathways. Adv Enzyme Regul 2006; 46: 154-161.

46. Byon CH, Javed A, Dai Q, Kappes JC, Clemens TL, Darley-Usmar $\mathrm{VM}$, et al. Oxidative stress induces vascular calcification through modulation of the osteogenic transcription factor Runx 2 by AKT signaling. J Biol Chem 2008; 283: 15319-15327.

47. Stinghen AEM, Chillon JM, Massy ZA, Boullier A. Differential effects of indoxyl sulfate and inorganic phosphate in a murine cerebral endothelial cell line (bEnd.3). Toxins 2014; 6: 1742-1760.

48. Chironi GN, Boulanger CM, Simon A, Dignat-George F, Freyssinet JM, Tedgui A. Endothelial microparticles in diseases. Cell Tissue Res 2009; 335: 143-151.

49. Di Marco GS, König M, Stock C, Wiesinger A, Hillebrand U, Reiermann S, et al. High phosphate directly affects endothelial function by downregulating annexin II. Kidney Int 2013; 83: 213-222.

50. Graciolli FG, Neves KR, dos Reis LM, Graciolli RG, Noronha IL, Moysés RM, et al. Phosphorus overload and PTH induce aortic expression of Runx2 in experimental uraemia. Nephrol Dial Transplant 2009; 24: $1416-1421$

51. Cozzolino M, Staniforth ME, Liapis H, Finch J, Burke SK, Dusso AS, et al. Sevelamer hydrochloride attenuates kidney and cardiovascular calcifications in long-term experimental uremia. Kidney Int 2003; 64: 1653-1661.

52. Lau WL, Linnes M, Chu EY, Foster BL, Bartley BA, Somerman MJ, et al. High phosphate feeding promotes mineral and bone abnormalities in mice with chronic kidney disease. Nephrol Dial Transplant 2013; 28: 62-69.

53. Phan O, Ivanovski O, Nguyen-Khoa T, Mothu N, Angulo J, Westenfeld $\mathrm{R}$, et al. Sevelamer prevents uremia-enhanced atherosclerosis progression in apolipoprotein E-deficient mice. Circulation 2005; 112: $2875-2882$.

54. Nikolov IG, Joki N, Nguyen-Khoa T, Guerrera IC, Maizel J, Benchitrit $\mathrm{J}$, et al. Lanthanum carbonate, like sevelamer-HCl, retards the progression of vascular calcification and atherosclerosis in uremic apolipoprotein E-deficient mice. Nephrol Dial Transplant 2012; 27: $505-513$.

55. Phan O, Ivanovski O, Nikolov IG, Joki N, Maizel J, Louvet L, et al. Effect of oral calcium carbonate on aortic calcification in apolipoprotein E-deficient (apoE-/-) mice with chronic renal failure. Nephrol Dial Transplant 2008; 23: 82-90.

56. Maizel J, Six I, Dupont S, Secq E, Dehedin B, Barreto FC, et al. Effects of sevelamer treatment on cardiovascular abnormalities in mice with chronic renal failure. Kidney Int 2013; 84: 491 -500.

57. Okano K, Wu S, Huang X, Pirola CJ, Juppner H, Abou-Samra AB, et al. Parathyroid hormone (PTH)/PTH-related protein $(\mathrm{PTHrP})$ receptor and its messenger ribonucleic acid in rat aortic vascular smooth muscle cells and UMR osteoblast-like cells: Cell-specific regulation by angiotensin-II and PTHrP. Endocrinology 1994; 135: 1093-1099.

58. Hagström E, Hellman P, Larsson TE, Ingelsson E, Berglund L, Sundström J, et al. Plasma parathyroid hormone and the risk of cardiovascular mortality in the community. Circulation 2009; 119: $2765-2771$

59. Noordzij M, Korevaar JC, Bos WJ, Boeschoten EW, Dekker FW, Bossuyt PM, et al. Mineral metabolism and cardiovascular morbidity and mortality risk: Peritoneal dialysis patients compared with haemodialysis patients. Nephrol Dial Transplant 2006; 21: 25132520.

60. Raggi P, Chertow GM, Torres PU, Csiky B, Naso A, Nossuli K, et al. The ADVANCE study: A randomized study to evaluate the effects of cinacalcet plus low-dose vitamin D on vascular calcification in patients on hemodialysis. Nephrol Dial Transplant 2011; 26: $1327-1339$.

61. EVOLVE Trial Investigators, Chertow GM, Block GA, CorreaRotter R, Drüeke TB, Floege J, Goodman WG, et al. Effect of cinacalcet on cardiovascular disease in patients undergoing dialysis. 
N Engl J Med 2012; 367: 2482-2494.

62. Lumachi F, Zanella S, Cella G, Casonato A, Fallo F. Endothelial activation markers soluble E-selectin and von Willebrand factor in primary hyperparathyroidism. In Vivo 2011; 25: 279-282.

63. Choi SR, Lim JH, Kim MY, Hong YA, Chung BH, Chung S, et al. Cinacalcet improves endothelial dysfunction and cardiac hypertrophy in patients on hemodialysis with secondary hyperparathyroidism. Nephron Clin Pract 2012; 122: 1-8.

64. Jono S, Nishizawa Y, Shioi A, Morii H. Parathyroid hormone-related peptide as a local regulator of vascular calcification: Its inhibitory action on in vitro calcification by bovine vascular smooth muscle cells. Arterioscler Thromb Vasc Biol 1997; 17: 1135-1142.

65. Shao JS, Cheng SL, Charlton-Kachigian N, Loewy AP, Towler DA. Teriparatide (human parathyroid hormone (1-34)) inhibits osteogenic vascular calcification in diabetic low density lipoprotein receptor-deficient mice. J Biol Chem 2003; 278: 50195-50202.

66. Neves KR, Graciolli FG, dos Reis LM, Graciolli RG, Neves CL, Magalhães AO, et al. Vascular calcification: Contribution of parathyroid hormone in renal failure. Kidney Int 2007; 71: 1262-1270.

67. Hénaut L, Boudot C, Massy ZA, Lopez-Fernandez I, Dupont S, Mary A, et al. Calcimimetics increase CaSR expression and reduce mineralization in vascular smooth muscle cells: Mechanisms of action. Cardiovasc Res 2014; 101: 256-265.

68. Ivanovski O, Nikolov IG, Joki N, Caudrillier A, Phan O, Mentaverri $\mathrm{R}$, et al. The calcimimetic R-568 retards uremia-enhanced vascular calcification and atherosclerosis in apolipoprotein E deficient (apoE-l-) mice. Atherosclerosis 2009; 205: 55-62.

69. Isakova T, Wahl P, Vargas GS, Gutiérrez OM, Scialla J, Xie H, et al. Fibroblast growth factor 23 is elevated before parathyroid hormone and phosphate in chronic kidney disease. Kidney Int 2011; 79: $1370-1378$.

70. Gutiérrez OM, Mannstadt M, Isakova T, Rauh-Hain JA, Tamez H, Shah A, et al. Fibroblast growth factor 23 and mortality among patients undergoing hemodialysis. N Engl J Med 2008; 359: 584-592.

71. Semba RD, Cappola AR, Sun K, Bandinelli S, Dalal M, Crasto C, et al. Plasma klotho and mortality risk in older community-dwelling adults. J Gerontol A Biol Sci Med Sci 2011; 66: 794-800.

72. Desjardins L, Liabeuf S, Renard C, Lenglet A, Lemke HD, Choukroun $\mathrm{G}$, et al. FGF23 is independently associated with vascular calcification but not bone mineral density in patients at various CKD stages. Osteoporos Int J 2012; 23: 2017-2025.

73. Tamei N, Ogawa T, Ishida H, Ando Y, Nitta K. Serum fibroblast growth factor-23 levels and progression of aortic arch calcification in non-diabetic patients on chronic hemodialysis. J Atheroscler Thromb 2011; 18: 217-223.

74. Mirza MAI, Larsson A, Lind L, Larsson TE. Circulating fibroblast growth factor- 23 is associated with vascular dysfunction in the community. Atherosclerosis 2009; 205: 385-390.

75. Kitagawa M, Sugiyama H, Morinaga H, Inoue T, Takiue K, Ogawa A, et al. A decreased level of serum soluble Klotho is an independent biomarker associated with arterial stiffness in patients with chronic kidney disease. PloS One 2013; 8: e56695, doi:10.1371/journal. pone.0056695.

76. Hu MC, Shi M, Zhang J, Quiñones $\mathrm{H}$, Griffith C, Kuro-o M, et al. Klotho deficiency causes vascular calcification in chronic kidney disease. J Am Soc Nephrol 2011; 22: 124-136.

77. Lim K, Lu TS, Molostvov G, Lee C, Lam FT, Zehnder D, et al.
Vascular Klotho deficiency potentiates the development of human artery calcification and mediates resistance to fibroblast growth factor 23. Circulation 2012; 125: 2243-2255.

78. Jimbo R, Kawakami-Mori F, Mu S, Hirohama D, Majtan B, Shimizu $\mathrm{Y}$, et al. Fibroblast growth factor 23 accelerates phosphate-induced vascular calcification in the absence of Klotho deficiency. Kidney Int 2013; 85: 1103-1111.

79. Ikushima M, Rakugi H, Ishikawa K, Maekawa Y, Yamamoto K, Ohta J, et al. Anti-apoptotic and anti-senescence effects of Klotho on vascular endothelial cells. Biochem Biophys Res Commun 2006; 339: $827-832$.

80. Rakugi H, Matsukawa N, Ishikawa K, Yang J, Imai M, Ikushima M, et al. Anti-oxidative effect of Klotho on endothelial cells through cAMP activation. Endocrine 2007; 31: 82-87.

81. Maekawa Y, Ohishi M, Ikushima M, Yamamoto K, Yasuda O, Oguro $\mathrm{R}$, et al. Klotho protein diminishes endothelial apoptosis and senescence via a mitogen-activated kinase pathway. Geriatr Gerontol Int 2011; 11: 510-516.

82. Kusaba T, Okigaki M, Matui A, Murakami M, Ishikawa K, Kimura $\mathrm{T}$, et al. Klotho is associated with VEGF receptor-2 and the transient receptor potential canonical-1 $\mathrm{Ca}^{2+}$ channel to maintain endothelial integrity. Proc Natl Acad Sci USA 2010; 107: 19308-19313.

83. Six I, Okazaki H, Gross P, Cagnard J, Boudot C, Maizel J, et al. Direct, acute effects of Klotho and FGF23 on vascular smooth muscle and endothelium. PloS One 2014; 9: e93423, doi:10.1371/journal. pone.0093423.

84. Memon F, El-Abbadi M, Nakatani T, Taguchi T, Lanske B, Razzaque MS. Does Fgf23-klotho activity influence vascular and soft tissue calcification through regulating mineral ion metabolism? Kidney Int 2008; 74: 566-570.

85. Kuro-o M, Matsumura Y, Aizawa H, Kawaguchi H, Suga T, Utsugi $\mathrm{T}$, et al. Mutation of the mouse klotho gene leads to a syndrome resembling ageing. Nature 1997; 390: 45-51.

86. Voigt M, Fischer DC, Rimpau M, Schareck W, Haffner D. Fibroblast growth factor (FGF)-23 and fetuin-A in calcified carotid atheroma. Histopathology 2010; 56: 775-788.

87. Faul C, Amaral AP, Oskouei B, Hu MC, Sloan A, Isakova T, et al. FGF23 induces left ventricular hypertrophy. J Clin Invest 2011; 121: $4393-4408$

88. Shalhoub V, Shatzen EM, Ward SC, Davis J, Stevens J, Bi V, et al. FGF23 neutralization improves chronic kidney disease-associated hyperparathyroidism yet increases mortality. J Clin Invest 2012; 122: $2543-2553$.

89. Lau WL, Leaf EM, Hu MC, Takeno MM, Kuro-o M, Moe OW, et al. Vitamin D receptor agonists increase klotho and osteopontin while decreasing aortic calcification in mice with chronic kidney disease fed a high phosphate diet. Kidney Int 2012; 82: 1261-1270.

90. Saito Y, Nakamura T, Ohyama Y, Suzuki T, Iida A, Shiraki-Iida T, et al. In vivo klotho gene delivery protects against endothelial dysfunction in multiple risk factor syndrome. Biochem Biophys Res Commun 2000; 276: 767-772.

91. Haenzi B, Bonny O, Masson R, Lienhard S, Dey JH, Kuro-o M, et al. Loss of Memo, a novel FGFR regulator, results in reduced lifespan. FASEB J 2014; 28: 327-336.

92. Uribarri J, Calvo MS. Hidden sources of phosphorus in the typical American diet: Does it matter in nephrology? Semin Dial 2003; 16: $186-188$. 